\title{
FL. DISCURSO-PROGRAMA EN LA TÉCNICA ANTICIPATORIA DE APOLONIO RODIO
}

Within the context of epic prolepsis and with numerous examples a device especially developed in Apollonius: the programatic-discourse', which consists of establishing a rigorous correspondance between the anticipation given by the speech of a character and the process of the narration that follows.

Uno de los rasgos más caracteristicos del género épico consiste en la anticipación de acontecimientos futuros en la narración, lo que C. Kraut bautizó a mediados del siglo pasado con el nombre de prolepsis épica en un estudio consagrado al análisis de este elemento en la Iliada ${ }^{\text {. }}$

La anticipación es una técnica ligada estrechamente al suspense en el relato, pero en absoluto ambas nociones resultan contradictorias. En efecto, G. E. Duckworth pudo demostrar, en contra de lo que se habia considerado por parte de algunos críticos, que un adecuado manejo de la prolepsis, manteniendo un equilibrio entre lo que se anticipa y lo que se silencia, es el mejor recurso para crear el suspense ${ }^{2}$.

Por otro lado, la anticipación de acontecimientos futuros es el recurso contrapuesto a la retrospección o analepsis. En ambos casos son puestas en conexión partes distintas de un mismo relato, diferentes mo-

1 Die epische Prolepsis nachgewiesen in der llias. Tubinga 1863.

2 Foreshadowing and Suspense in the Epics of Homer. Apollonius and Vergil. Princeton 1933. En este sentido el análisis comparativo de los tres grandes poetas épicos de la antigüedad realizado por Duckworth mostraba algunas diferencias en el manejo de la anticipación y el suspense. La técnica homérica consigue una elevación progresiva del suspense mediante un juego entre las reiteradas anticipaciones al lector y la retardación del acontecimiento anunciado. En cambio, Apolonio y Virgilio, que siguen en parte la técnica homérica, desarrollan simultáneamente, sobre todo el poeta latino, un nuevo tipo de suspense consistente en crear incertidumbre en el lector por la vaguedad e imprecisión de las anticipaciones. Cf. o.c., pp. 26, 116-22. 
mentos del desarrollo narrativo, de modo que tales correferencias intratextuales contribuyen a la unidad y cohesión interna de un determinado texto narrativo. Esta es la perspectiva bajo la que W. Schadewaldt llevó a cabo un análisis de tales elementos en el canto XI de la Iliada para demostrar la unidad del poema, concebido de modo coherente y total por un creador único ${ }^{3}$.

En cuanto a su forma de presentación en el texto, la anticipación puede ser efectuada por el propio narrador, como figura omnisciente, o bien por un personaje, ya sea de naturaleza divina o humana. Asimismo resulta de sumo interés distinguir si la anticipación va dirigida solamente al lector o también a los personajes del relato. Una clasificación de este tipo fue elaborada por 1 . Wieniewski en su estudio de la técnica anticipatoria en Homero ${ }^{4}$, y ha sido seguida en lo fundamental por Duckworth.

Desde otro punto de vista puede establecerse una diferencia importante según el grado de especificación de las anticipaciones. En ocasiones se anuncia determinado acontecimiento futuro o bien el resultado de la acción. Pero otras veces se trata de una anticipación vaga y genérica en torno al desarrollo de la acción futura ${ }^{5}$. Este tipo de anticipación genérica alcanza en Apolonio y Virgilio un relieve mucho mayor del que poseia en los poemas homéricos, lo cual guarda cierta correspondencia con la naturaleza del procedimiento formal empleado. Así, en las Argonáuticas, en concreto, las anticipaciones efectuadas por personajes divinos y dirigidas sólo al lector son mucho menos numerosas que en Homero, mientras que Apolonio hace un uso mayor de los signos proféticos y de los personajes humanos como medios de anticipación dirigidos simultáneamente al lector y a los personajes ${ }^{6}$.

Pues bien, en el marco de esta segunda variedad de anticipación, que no anuncia puntualmente el resultado o el cumplimiento de una acción determinada, sino que indica, en un sentido general, cuál será el curso posterior de los acontecimientos en el relato, pretendemos analizar aqui una forma particular de anticipación, enmarcada en el discurso de un personaje $y$, por consiguiente, dirigida tanto al lector como al resto de personajes, que representa un tipo muy desarrollado en el poema de Apolonio y de escasa presencia en el modelo homérico. Se trata de lo que llamaremos el discurso-programa, en virtud del cual un persona-

\footnotetext{
3 Iliasstudien, Leipzig 1938.

4 "La technique d'annoncer les événements futurs chez Homère», Eos 27, 1924, pp. 113-133.

5 Sobre estos dos niveles de anticipación, cf. Duckworth, o.c., p. 6.

- Cf. Duckworth, o.c., pp. 18-20.
} 
je propone a los demás el plan de actuación a seguir, plan que constituye un bosquejo del desarrollo narrativo subsiguiente.

Uno de los ejemplos más relevantes de discurso-programa en las $\mathrm{Ar}$ gonáuticas está representado por las palabras que Jasón dirige a sus compañeros tras ser proclamado jefe de la expedición (A.R., I 351-362). En efecto, el discurso del Esónida contiene un verdadero proyecto de actuación, que anticipa en líneas generales el desarrollo narrativo de los próximos versos, dedicados a los preparativos para el inicio del viaje. En concreto las dos escenas siguientes, la botadura de la nave (A.R., I 363-401) y el sacrificio en honor de Apolo (A.R., I 402-449) quedan anunciadas de manera clara. La última escena previa a la partida, el banquete y la riña entre los Argonautas (A.R., I 450-518), también ha sido prefigurada, aunque de modo más débil, con la referencia al festín (v. 354) que celebrarán los héroes. (Véase Cuadro n. ${ }^{\circ}$ 1.) En este caso el valor del discurso programático como orientación del relato sucesivo viene complementado en parte por la naturaleza del personaje que habla: Jasón, como jefe de la expedición, organiza el curso de los acontecimientos ${ }^{7}$.

\begin{tabular}{|c|c|c|}
\hline & Cuadro 1 & \\
\hline $\begin{array}{l}\text { Discurso de Jasón } \\
\text { I .351-362 }\end{array}$ & & $\begin{array}{l}\text { Narración } \\
\text { I 363-518 }\end{array}$ \\
\hline $353-356$ & sacrificios y festin & \\
\hline $357-358$ & botadura de la nave & $363-401$ \\
\hline $359-362$ & construcción de un altar & $402-449$ \\
\hline (354) & festin & (450 ss.) \\
\hline
\end{tabular}

Ciertamente en determinadas ocasiones es alguno de los dioses quien interviene programando anticipadamente el curso de la acción futura, y se erige de este modo en conductor del relato. Asi ocurre en A.R., III 25-29, donde Hera planifica en un breve discurso el desarrollo de los acontecimientos en la Cólquide ${ }^{\gamma}$. Pero, sobre todo, alcanzan es-

7 Precisamente a propósito de este lugar ha señalado F. Vian (Apollonios de Rhodes. Argonautiques, Paris 1976-1981, I, p. 15) que nuestro poeta gusta de "anunciar las grandes lineas del relato mediante una serie de prescripciones», tal como sucede en el presente caso, donde «Jasón fija el programa que será respetado escrupulosamente». En otro lugar (p. 120) insiste el autor francés: "Apollonios aime faire précéder ses recits d'un discours-programme".

${ }^{*}$ Las palabras de Hera anuncian de manera precisa la escena olimpica siguiente en casa de Afrodita (A.R., III 36-112), la intervención de Eros para enamorar a Me- 
pecial relieve las intervenciones sucesivas de Hera y de Tetis, que a lo largo de un extenso pasaje (A.R., IV 753-887) preparan mediante una serie de discursos el desarrollo del próximo episodio (A.R., IV 887-964) sobre las dificultades marinas ${ }^{9}$. Sin embargo, en tales casos el discurso va dirigido a otra divinidad, de modo que nos encontramos ante una categoría anticipatoria distinta, puesto que únicamente el lector y no el conjunto de personajes se beneficia de lo anunciado.

También personajes dotados de cierto soplo divino, como profetas y adivinos, verifican a veces sus vaticinios mediante un discurso-programa. En este sentido los discursos proféticos de Fineo (A.R., II 311-407 y $420-425$ ) representan el ejemplo más sobresaliente ${ }^{10}$. En particular el primero de ellos es bastante extenso y especifica tanto indicaciones geográficas, que guian el periplo marítimo de los Argonautas, como instrucciones sobre la actuación de los héroes. Tal discurso constituye un verdadero programa-guía detallado del viaje de los héroes hasta su llegada a la Cólquide con referencia explícita a todos y cada uno de los episodios que se sucederán a lo largo del libro II ". (Véase Cuadro n. ${ }^{\circ}$ 2.)

En todo caso la forma literaria del discurso-programa adquiere plena significación por sí misma en el poema de Apolonio, cuando son otros personajes los que anticipan el curso del relato. Diversos ejemplos pueden ser mostrados para testimoniar cómo el poeta de Rodas acos-

dea (A.R., III 275-298) y, de un modo más general, la ayuda de ésta en reiteradas ocasiones hasta el regreso a Grecia con el vellocino.

4 Dos son los discursos de Hera (A.R., IV 757-769 y 818-832) y otros dos los de Tetis (A.R.. IV 834-841 y 856-864), el último de los cuales, dirigido a Peleo, tiene por finalidad transmitir a los Argonautas los planes que ambas diosas han programado para superar tales dificultades (Sirenas, Escila y Caribdis, Rocas Errantes). Este pasaje argonáutico guarda estrecha semejanza con su correspondiente de la Odisea, donde un discurso de la diosa Circe (XII 37-141) detalla instrucciones a Ulises para vencer las dificultades del regreso (Sirenas, Escila y Caribdis, Vacas del Sol), cuya narración será desarrollada a lo largo del resto del canto XII (vv. 142453).

10 El segundo discurso contiene anticipaciones muy concisas pero significativas: la importante ayuda de Afrodita en el libro III y la guia de una divinidad en el regreso (libro IV). En torno a las profecías de Fineo puede verse Duckworth, o.c., pp. 82 s., 101 s.; K. W. Blumberg, Untersuchungen zur epischen Technik des Apollonios von Rhodos, Leipzig 1931, pp. 35-40; L. Hensel, Weissagungen in der alexandrinischen Poesie. Diss. Giessen 1908, pp. 25-27; D. N. Levin, Apollonius' Argonautica re-examined I, Leiden 1971, pp. 155-162; Vian, o.c., I, p.120 s.

"En la poesia homérica, además del mencionado discurso de la diosa Circe en $O d$. XII 37-141, un ejemplo parecido es la profecía de Tiresias (Od. XI 100-137), pero ésta anuncia más bien hechos puntuales relativos a la liberación final de los extravios de Odiseo y no supone un programa de la narración posterior. Sobre la diferencia entre el ejemplo homérico y el de Apolonio en cuanto al mayor suspense creado por este último, cf. Duckworth, o.c., p. 83. 


\begin{tabular}{|c|c|c|}
\hline & Cuadro 2 & \\
\hline $\begin{array}{l}\text { Discurso de Fineo } \\
\text { II } 311-407\end{array}$ & & $\begin{array}{c}\text { Narración } \\
\text { II } 549-1285\end{array}$ \\
\hline $311-316$ & proemio a la profecia & \\
\hline $317-345$ & episodio Simplégades & $549-648$ \\
\hline $345-350$ & navegación (geografia) & $648-721$ \\
\hline $351-356$ & episodio de Lico & $722-898$ \\
\hline $357-381 \mathrm{~b}$ & navegación (geografia) & $899-1025$ \\
\hline $382-391$ & episodio isla de Ares & $1030-1227$ \\
\hline $392-396$ & navegación (geografia) & $1228-125$ \\
\hline $396-407$ & Ilegada a la Cólquide & $1260-128$ \\
\hline
\end{tabular}

tumbra a ofrecer, mediante el discurso de un personaje humano dirigido a los demás héroes, un programa anticipado de la acción futura $\mathrm{y}$, por consiguiente, del desarrollo narrativo posterior. Asi, cuando los Argonautas se acercan a la isla de Ares, uno de los héroes, Anfidamante, propone a los demás una estratagema para dispersar las peligrosas aves de Ares, de modo que la segunda parte de su discurso (A.R., II 10601067) funciona como un programa que prefigura la narración posterior del poeta (A.R., II 1069-1089) sobre la puesta en práctica de tal artimaña. (Véase Cuadro n. ${ }^{\circ}$ 3.) De modo semejante, tras la muerte de Apsirto, Peleo expone brevemente a sus compañeros un plan para evitar el enfrentamiento directo con los Colcos (A.R., IV 495-502) y acto seguido el poeta desarrolla el relato de los hechos (A.R., IV 504-528), que se corresponde en forma amplificada con el esquema anunciado por el personaje. (Véase Cuadro $n .^{\circ} 4$.) Por último, añadiremos otro ejemplo que presenta alguna variación con respecto a los demás discursos-programa. Cuando Eetes se ha informado del motivo de la expedición argonáutica, irritado dirige un discurso a Jasón imponiéndole duras condiciones para la entrega del vellocino. Sus palabras finales (A.R., III

\begin{tabular}{|c|c|c|}
\hline & Cuadro 3 & \\
\hline $\begin{array}{c}\text { Discurso de Anfidamante } \\
\text { II } 1060-1067\end{array}$ & & $\begin{array}{c}\text { Narración } \\
\text { II } 1069-1089\end{array}$ \\
\hline $1060-1062$ & encubrimiento de la nave & $1069-1076$ \\
\hline $1063-1065$ & griterio & $1077-1079$ \\
\hline $1066-1067$ & ruido con los escudos & $1080-1089$ \\
\hline
\end{tabular}




\begin{tabular}{|c|c|c|}
\cline { 2 - 3 } \multicolumn{1}{c|}{ Cuadro 4 } & \multicolumn{1}{c|}{} \\
\cline { 2 - 3 } \multicolumn{1}{c|}{$\begin{array}{c}\text { Discurso de Peleo } \\
\text { IV 495-502 }\end{array}$} & & $\begin{array}{c}\text { Narración } \\
\text { IV 504-528 }\end{array}$ \\
\hline $495-497$ & embarque para retroceder & $504-506$ \\
\hline $497-500$ & desánimo y dispersión de los Colcos & $507-521$ \\
\hline $501-502$ & prosecución del viaje & $522-528$ \\
\hline
\end{tabular}

407-420) no suponen un plan de actuación, sino más bien una imposición aparentemente irrealizable, pero con el transcurso de la narración vienen a ser, no obstante, un esquema anticipado del relato posterior (A.R., III 1278-1407) sobre el cumplimiento de las pruebas por Jasón. (Véase Cuadro n. ${ }^{\circ}$ 5.)

Deliberadamente vamos a presentar agrupados al final una serie de discursos-programa ubicados en los libros III y IV de las Argonáuticas, que tienen como rasgo común el ser pronunciados por Medea y que constituyen la manifestación más elaborada y genuina de este tipo de recurso anticipatorio en nuestro poeta. El primero de ellos, ciertamente el más complejo, contiene en una exposición detallada los consejos e indicaciones que la joven princesa facilita a Jasón para el cumplimiento de las pruebas (A.R., III 1026-1062). Estas recomendaciones de Medea son una anticipación, dirigida tanto al lector como al propio Jasón, que programa paso a paso y en estricta correspondencia (véase Cuadro $n .^{\circ}$ 6) los hechos relatados por el poeta en la última escena del libro III, así como en los preparativos que la preceden (A.R., III 1172-1407). La importancia que para el desarrollo de la acción posee la ayuda declarada por Medea en este discurso, asi como el relieve conferido por el poeta a la parte final del libro III, concebida como culminación del episodio de la Cólquide, hacen del presente discurso-programa anticipatorio un elemento clave para el desenvolvimiento y la configuración del relato en

\begin{tabular}{|c|c|c|}
\hline & Cuadro 5 & \\
\hline $\begin{array}{l}\text { Discurso de Eetes } \\
\text { III } 407-420\end{array}$ & & $\begin{array}{l}\text { Narración } \\
\text { III 1278-1407 }\end{array}$ \\
\hline $407-412$ & uncir los toros & $1278-1320$ \\
\hline $412-415$ & siembra de los dientes del dragón & $1320-1347$ \\
\hline $415-416$ & matanza de los terrigenos & $1354-1398$ \\
\hline $417-420$ & $\ldots \ldots \ldots \ldots \ldots \ldots \ldots \ldots \ldots$ & $1399-1407$ \\
\hline
\end{tabular}




\begin{tabular}{|c|c|c|}
\hline & Cuadro 6 & \\
\hline $\begin{array}{l}\text { Discurso de Medea } \\
\text { III 1026-1062 }\end{array}$ & & $\begin{array}{c}\text { Narración } \\
\text { III } 1172-1407\end{array}$ \\
\hline 1026 & introducción: ayuda & \\
\hline $1027-1041$ & rito de sacrificio a Hécate & $1194-1224$ \\
\hline $1042-1045$ & filtro: fortaleza de Jasón & $1256-1270$ \\
\hline $1046-1047$ & filtro: untar las armas & $1246-1255$ \\
\hline $1047-1060$ & $\begin{array}{l}\text { Trubajos de Jasón } \\
(1052) \quad \text { : uncir los toros } \\
(1052-1053) \text { : arar el campo } \\
(1054-1055) \text { : nacimiento de espartos } \\
(1056-1060) \text { : lanzamiento de piedra }\end{array}$ & $\begin{array}{l}1288-1320 \\
1320-1347 \\
1354-1363 \\
1363-1376\end{array}$ \\
\hline $1060-1062$ & rescate del vellocino - regreso & libro IV \\
\hline
\end{tabular}

la parte central del poema, precisamente donde la narración de la empresa argonáutica alcanza su momento cumbre ${ }^{12}$.

El siguiente discurso-programa de Medea se encuentra ya en el libro IV del poema. Cuando la heroina ha resuelto huir con los Argonautas, pronuncia entonces un breve discurso (A.R., IV 83-91) ofreciendo a los héroes un plan de actuación, que prefigura, aunque sea de modo conciso, el desarrollo subsiguiente del episodio (A.R., IV 95-211) y establece con éste una correspondencia de estructura quiástica. (Véase Cuadro n." 7.) De nuevo en este caso las palabras de Medea orientan el curso

\begin{tabular}{|c|c|c|}
\hline & Cuadro 7 & \\
\hline $\begin{array}{l}\text { Discurso de Medea } \\
\text { IV } 83-91\end{array}$ & & $\begin{array}{l}\text { Narración } \\
\text { IV 95-211 }\end{array}$ \\
\hline $83-85$ & exordio & \\
\hline $85-86$ & huida & $206-211$ \\
\hline $87-88$ & rescate del vellocino & $100-189$ \\
\hline $88-91$ & promesa de matrimonio & $95-100$ \\
\hline
\end{tabular}

12 Un lugar homérico guarda cierta semejanza con el discurso de Medea en su primera parte: el discurso de $\mathrm{Od}$. X 504-540, en el que la diosa Circe detalla instrucciones a Ulises sobre el modo de realizar la consulta al adivino Tiresias acerca del regreso, instrucciones rituales que son cumplidas por Odiseo en XI 1-137, de modo paralelo a las verificadas por Jasón (A.R., III 1194-1224) a instancias de Medea (A.R., III 1027-1041) para propiciarse a la diosa Hécate. 


\begin{tabular}{|c|c|c|}
\cline { 2 - 3 } \multicolumn{1}{c|}{} & \multicolumn{1}{c|}{ Cuadro 8 } \\
\hline $\begin{array}{c}\text { Discurso de Medea } \\
\text { IV 411-420 }\end{array}$ & & $\begin{array}{c}\text { Narración } \\
\text { IV 421-491 }\end{array}$ \\
\hline 416 & regalos & $421-434$ \\
\hline $417-418$ & engaño de Medea & $435-444$ \\
\hline $419-420$ & muerte de Apsirto & $452-481$ \\
\hline $414-420$ & ataque a los Colcos & $482-491$ \\
\hline
\end{tabular}

posterior de la acción en un punto muy destacado del relato, donde el poeta se dispone a narrar la obtención del vellocino, objetivo básico de la expedición.

En el episodio de las islas Apsírtides los Argonautas se encuentran en situación de grave dificultad y ha de ser también Medea quien proponga un dramático plan para salir del apuro. Las palabras de la doncella (A.R., IV 411-420) corren de forma enteramente simétrica a la narración que el poeta trazará seguidamente y con mayor amplitud en torno al asesinato de Apsirto (A.R., IV 421-491), de tal manera que, una vez más, el discurso de Medea constituye un programa anticipado que guía el desarrollo posterior de los acontecimientos. (Véase Cuadro n. ${ }^{\circ} 8$.)

Finalmente, con motivo de la breve escala de los Argonautas en Creta tiene lugar la última intervención de Medea. Ante la hostilidad del gigante Talos la heroina se adelanta nuevamente a proponer un plan de actuación (A.R., IV 1654-1658), que será desarrollado en la narración posterior del poeta (A.R., IV 1659-1688). Pero esta vez tanto la brevedad de su discurso como la extrema imprecisión de lo anticipado confluyen para que apenas podamos hablar de un discurso-programa, aunque desde luego responde al mismo procedimiento y situación narrativa que los mencionados anteriormente ${ }^{13}$.

Asi pues, el discurso-programa como procedimiento anticipatorio se caracteriza por anunciar el proceso que seguirá la acción $\mathrm{y}$, por consiguiente, constituye siempre un esquema-guia de la narración posterior. No obstante, en contraste con este tipo de prolepsis, también tiene cabida en el mismo texto de las Argonáuticas esa otra categoría de discursos que, siguiendo la práctica homérica, anuncian de manera puntual el resultado final de una acción. Un ejemplo notorio es el discurso del adivi-

13 Puede servir como justificación el hecho de que el episodio de Talos es el menos desarrollado narrativamente de todo el poema y el menos integrado en la estructura general, como ya apuntara Vian, o.c.. III, p. 55. 
no Idmón en A.R., I 440-447, que vaticina el destino reservado a los Argonautas: el éxito final de la expedición y la muerte del propio Mopso.

Llegados a este punto, parece conveniente dirigir una mirada retrospectiva a la situación de la épica arcaica. En Homero los discursos anticipatorios pueden ser de diferentes clases, pero apenas si alguno de ellos responde al tipo de discurso-programa desarrollado por Apolonio. Así, en los dos poemas homéricos, donde la presencia e intervención de los dioses es mucho mayor que en las Argonáuticas, destacan sendos discursos de Zeus, en los que da a conocer de antemano cuál será la resolución final del conflicto de acuerdo con el destino que aguarda a los héroes ${ }^{14}$. Pero estas decisiones divinas no contienen un programa de la narración posterior, sino que poseen el carácter de anticipaciones puntuales; y además son anunciadas sólo al lector, mientras que los personajes humanos permanecen ignorantes de tales designios. En la Iliada un personaje como Néstor acostumbra también a intervenir dando consejos acerca de la actuación futura, pero el relato homérico posterior no guarda correspondencia estricta con sus discursos ${ }^{15}$.

Un caso muy semejante al tipo de discurso-programa apoloniano, y que probablemente debe ser puesto como su modelo primario, es el discurso de Atenea a Ulises en $O d$. XIII 397-415 y, sobre todo, el discurso en el que este último expone a su hijo Telémaco el plan de actuación contra los pretendientes ( $\mathrm{Od}$. XVI 267-307). Efectivamente aqui se establece una correspondencia entre lo anunciado por el personaje en su discurso y lo desarrollado luego por el poeta en la narración, aunque en verdad el transcurso del relato experimente algunas modificaciones con respecto a lo programado. (Véase Cuadro n." 9.)

En definitiva, podemos destacar a modo de conclusión que Apolonio, además de utilizar los tipos de anticipación propios de Homero, ha desarrollado una nueva categoria consistente en hacer que el discurso de un personaje, generalmente humano, preceda a la narración del poeta y le sirva de programa. Esta nueva categoria se define por la presen-

14 En Od. V 29-42 expresa Zeus su designio de que Ulises alcance finalmente el regreso a la patria. De igual modo en 11 . XV 49-77 Zeus expone su firme determinación acerca de la resolución del conflicto, asi como sobre la suerte que deberán correr determinados héroes.

is Pueden verse, por ejemplo, II. VII 327-43. IX 163-72... En este sentido (y a propósito del discurso de Jasón en A.R., I 351-62) H. Fraenkel (Noten zu den Argonautika des Apollonios, Munich 1968, p.70) ha puesto de relieve cómo Apolonio sigue la práctica de la epopeya arcaica haciendo que un discurso preceda a la ejecución de los hechos, pero en cambio se aparta de Homero al atenerse en el relato posterior estrictamente a lo ordenado en el discurso. 


\begin{tabular}{|c|c|c|}
\hline & Cuadro 9 & \\
\hline $\begin{array}{c}\text { Discurso de Ulises } \\
\text { XVI 267-307 }\end{array}$ & & Narración \\
\hline $270-271$ & regreso de Telémaco & XVII $1-30$ \\
\hline $272-273$ & regreso de Ulises & XVII $182-261,336 \ldots$ \\
\hline $273-280$ & ultrajes a Ulises & $\begin{array}{l}\text { XVII 342-XVIII } 157 \\
\text { XVIII 346-428 }\end{array}$ \\
\hline $281-298$ & ocultación de las armas & XIX 1-50 \\
\hline 299-307 & prueba a los sirvientes & $\begin{array}{l}\text { XVIII 304-342 } \\
\text { XIX 65-96 }\end{array}$ \\
\hline
\end{tabular}

cia de un rasgo que apenas podemos rastrear en la poesía homérica, a saber, el establecimiento de una correspondencia estricta entre lo anunciado en esquema por el personaje y lo desarrollado por el poeta en la narración amplificada.

El estilo de Apolonio en estos dobletes responde fundamentalmente a la nueva poética helenística, por cuanto evita las repeticiones, tanto a nivel de contenido mediante un juego de resumen/amplificación del relato, como a nivel estilístico mediante la técnica de la imitatio cum uariatione de sí mismo ${ }^{16}$.

Una prueba de la novedad que supone esta categoría apoloniana de anticipación con respecto al modelo homérico reside en que la mayor parte de los discursos-programa aquí analizados no están incluidos en los estudios sobre la técnica anticipatoria de Apolonio, ya que no responden a los tipos tradicionales. Solamente las profecías de Fineo y el primer discurso de Medea han sido objeto de atención hasta ahora en la bibliografia sobre el tema ${ }^{17}$.

Por lo demás, el hecho de que en Apolonio tales discursos-programa sean pronunciados esencialmente por personajes humanos hace que éstos adquieran un relieve notable en la narración, al convertirse en guías que orientan con sus intervenciones el curso de la acción en el relato. Así, en el caso particular de los discursos de Medea, según hemos visto,

16 Hemos tenido ocasión de analizar en profundidad esta técnica apoloniana a propósito de un ejemplo concreto: "Las instrucciones de Medea como discurso-programa en A.R., III 1026-1062", Actas del VII Congreso Español de Estudios Clásicos, en prensa.

${ }_{17}$ Incluso el reciente trabajo de M. Fusillo (Il tempo delle Argonautiche, Roma 1985), que dedica casi toda la primera parte (pp. 23-158) a estudiar de manera sistemática las analepsis y prolepsis en el poema de Apolonio, ha pasado por alto los restantes lugares aqui aducidos. 
además de la importancia en sí mismos como elementos literarios de anticipación, alcanzan un significado especial para la comprensión del poema en su totalidad, en la medida en que son un fiel exponente de la preeminencia conseguida por la heroina: efectivamente la ayuda y salvación facilitadas por ella en muchos momentos dificiles ante la á $\mu \eta \chi a v i ́ \eta$ de Jasón vienen canalizadas a través de estas intervenciones. Y en ese sentido los discursos-programa de Medea constituyen un instrumento literario eficaz, que sirve para elevar a este personaje femenino al primer plano del relato, por encima incluso del propio Jasón.

Mariano Valverde Sánchez 